\title{
New Canadian guidance on opioid use for chronic pain: necessary but not sufficient
}

\author{
Andrea D. Furlan MD PhD, Owen D. Williamson MBBS
}

- Cite as: CMAJ 2017 May 8;189:E650-1. doi: 10.1503/cmaj.170431

See related article www.cmaj.ca/lookup/doi/10.1503/cmaj.170363

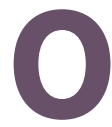

pioid-related deaths are more prevalent in Canada today than 10 years ago. ${ }^{1}$ People between 25 and 34 years of age are most affected. ${ }^{2}$ Although the drivers of this public health crisis are complex, it has been suggested that unsafe prescribing of opioids to patients with pain has contributed to the problem. ${ }^{3}$ However, a less well-publicized problem of undertreated chronic pain also exists. One in five Canadians lives with chronic pain. ${ }^{4}$ The aim of the 2017 update of the Canadian Guideline for Opioid Therapy and Chronic Noncancer Pain is to promote safer and more effective opioid prescribing to the small proportion of patients with chronic noncancer pain who may benefit from their use, and this may well be achieved. ${ }^{5}$ However, the new recommendations are unlikely to solve either Canada's opioid crisis or the undertreatment of those living with persistent pain.

The Canadian Guideline for Opioid Therapy and Chronic Noncancer Pain was developed using strict methodological protocols. Recommendations were supported by strong, consistent evidence. When evidence was insufficient to support recommendations, expert opinion was used to develop good practice statements. Evidence was available to support only four "strong" recommendations and six "weak" recommendations. A strong recommendation can be interpreted as "should" and a weak recommendation as "consider it." The recommended upper dose of prescribed opioids has been reduced from that stated in the 2010 guideline, which defined a "watchful dose" as $200 \mathrm{mg}$ of morphine equivalent per day (MED). ${ }^{6}$ The 2017 guideline recommends an upper dose of $90 \mathrm{mg}$ MED, in line with the US Centers for Disease Control Guideline for Prescribing Opioids for Chronic Pain. ${ }^{7}$ This upper dose limit is based largely on the evidence of harms, which shows correlations between higher doses and increasing risks of death. ${ }^{8}$

The updated guideline applies to all professionals who prescribe opioids for chronic pain, including family physicians, specialists and nurse practitioners. Its authors recognize that although the majority of patients are expected to fall into the categories described, a small proportion of patients may not and will require special consideration. The recommendation that the prescribed dose of opioids be restricted to less than 90 mg MED recognizes that some patients may benefit from a higher dose,

\section{KEY POINTS}

- Opioid deaths are increasing in prevalence in Canada and unsafe prescribing of opioids has been identified as a contributor to the problem.

- However, a less well-publicized problem of undertreated chronic pain also exists.

- The 2017 Canadian Guideline for Opioid Therapy and Chronic Noncancer Pain is welcome, yet health system barriers to accessing safe, effective and affordable alternative multimodal pain treatments limit their practical use.

- Until Canada has a realistic national strategy for the treatment of chronic disabling pain, physicians will continue using the only tool they have in their toolbox: their prescription pad.

but suggests that if this is the case, a second opinion is required. Similarly, patients who are already receiving doses higher than $90 \mathrm{mg}$ (legacy or inherited patients) should be offered a trial of tapering to the lowest possible dose, but it is recognized that tapering may be paused and potentially abandoned in some patients who have substantial increase in pain or decrease in function during tapering. Regulators will, therefore, need to be made aware that there is a small but definite role for the use of opioids in managing chronic noncancer pain, and that overregulating prescribers so they cannot undertake trials of safe and effective therapies would be unhelpful.

No guideline can account for the unique features of patients and their clinical circumstances, and the new guideline is not meant to replace clinical judgment. Patients, prescribers and other stakeholders, including regulators and insurers, should not view its recommendations as absolute. Statements about qualifying remarks and values and preferences are integral parts of the recommendations and are meant to facilitate accurate interpretation of the guideline.

Implementing the guideline's recommendations in clinical practice may be challenging, as prescribers may have insufficient skills, resources or time to do so. Patients may resist change because they have unrealistic expectations or false beliefs that opioids can eliminate their pain completely, or because they fear withdrawal 
symptoms or do not trust that their prescribers are changing their prescriptions because it is in the patient's best interests.

Systemic barriers include the lack of timely access to alternative safe, effective and affordable multimodal pain treatments. There are long waiting lists to access multidisciplinary pain clinics and pain management specialists, and few community-based self-management programs. ${ }^{9}$ Managing patients with chronic pain requires a system that is able to offer attention, explanation, reassurance and empathy. If health providers can afford the time to address the complexity of issues presented by these patients, alternatives to opioids can be explored and the risk of opioids avoided. However, health care professionals receive inadequate education about chronic pain in undergraduate, residency and continuing professional development programs. ${ }^{10}$ Current funding models do not account adequately for the time required to address patients who present with the complex interaction of chronic pain, sleep and mood disorders and, in some cases, substance abuse.

The updated guideline will not address the public health crisis related to opioids without support from a comprehensive national pain strategy to ensure evidence-based alternative treatments for the one in five Canadians currently living with chronic pain. The guideline recommends that patients with chronic noncancer pain be offered a trial of opioids only after they have been optimized on nonopioid therapy, including nondrug measures. This underscores the need to improve patients' access to pain education, self-management programs, physical therapies, psychological interventions, nonopioid drugs, complementary and alternative medicine, social supports, and interven- tional pain and surgical treatments. Finestone and colleagues called opioid prescribing a surrogate for inadequate pain management resources, and we wholeheartedly agree. ${ }^{11}$ Health care providers need more tools in their toolbox for the management of patients with chronic pain. Until we have a national pain strategy, physicians will continue using the only tool they have: their prescription pad.

\section{References}

1. Fischer B, Rehm J. Revisiting the "paradigm shift" in opioid use: developments and implications 10 years later. Drug Alcohol Rev 2017 Mar. 23 [EPub ahead of print]. doi: 10.1111/dar.12539

2. Gomes T, Mamdani MM, Dhalla IA, et al. The burden of premature opioidrelated mortality. Addiction 2014;109:1482-8.

3. Gomes T, Juurlink D, Moineddin R, et al. Geographical variation in opioid prescribing and opioid-related mortality in Ontario. Healthc Q 2011;14:22-4.

4. Schopflocher D, Taenzer P, Jovey R. The prevalence of chronic pain in Canada. Pain Res Manag 2011;16:445-50.

5. Busse JW, Craigie S, Juurlink DN, et al. Guideline for opioid therapy and chronic noncancer pain. CMAJ 2017;189:E659-66.

6. Furlan $A D$, Reardon $R$, Weppler $C$. Opioids for chronic noncancer pain: a new Canadian practice guideline. CMAJ 2010;182:923-30.

7. Centers for Disease Control and Prevention Public Health Service US Department of Health and Human Services. Guideline for prescribing opioids for chronic pain. J Pain Palliat Care Pharmacother 2016;30:138-40.

8. Gomes T, Mamdani MM, Dhalla IA, et al. Opioid dose and drug-related mortality in patients with nonmalignant pain. Arch Intern Med 2011;171:686-91.

9. Choinière $M$, Dion $D$, Peng $P$, et al. The Canadian STOP-PAIN project - part 1 : Who are the patients on the waitlists of multidisciplinary pain treatment facilities? Can J Anaesth 2010;57:539-48.

10. Watt-Watson J, McGillion M, Hunter J, et al. A survey of prelicensure pain curricula in health science faculties in Canadian universities. Pain Res Manag 2009; 14:439-44.

11. Finestone HM, Juurlink DN, Power B, et al. Opioid prescribing is a surrogate for inadequate pain management resources. Can Fam Physician 2016;62:465-8.
Competing interests: Owen Williamson reports nonfinancial support from Health Canada and personal fees and nonfinancial support from Purdue Pharma (Canada), Mundipharma International Ltd. and INVIVO Communications Ltd., outside the submitted work. Andrea Furlan is acknowledged in the guideline published in this issue of CMAJ. She participated in the first meeting of the clinical experts in January 2016 but was not involved in the remaining development of the guideline.

Affiliations: Toronto Rehabilitation Institute (Furlan), University Health Network; Institute for Work and Health (Furlan); Department of Medicine (Furlan), University of Toronto, Toronto, Ont.; Department of Epidemiology and Preven- tive Medicine (Williamson), Monash University, Melbourne, Australia; Pain Management Clinic (Williamson), Fraser Health Authority, Surrey, BC

This article was solicited and has not been peer reviewed.

Correspondence to: Andrea Furlan, andrea. furlan@uhn.ca 